\title{
Correction to: How do peace dividends bring about human development and productivity?
}

\author{
Wen-Min $\mathrm{Lu}^{1} \cdot$ Qian Long Kweh² ${ }^{2} \cdot \mathrm{Kang}-\mathrm{Fu} \mathrm{Chen}{ }^{3}$ \\ ๑) Springer Science+Business Media, LLC, part of Springer Nature 2021
}

\section{Correction to: Annals of Operations Research (2021) 306:435-452 https://doi.org/10.1007/s10479-021-04285-9}

Greek symbols \& equations in section 3.2 were rendered incorrectly due to proofing error.

Original article has been updated.

Publisher's Note Springer Nature remains neutral with regard to jurisdictional claims in published maps and institutional affiliations.

The original article can be found online at https://doi.org/10.1007/s10479-021-04285-9.

\footnotetext{
Qian Long Kweh

qlkweh@gmail.com

Wen-Min Lu

wenmin.lu@gmail.com

Kang-Fu Chen

gangfu.chen101@gmail.com
}

1 Department of International Business Administration, Chinese Culture University, No. 55,

Hwa-Kang Road, Shilin District, Taipei 114, Taiwan

2 Faculty of Management, Canadian University Dubai, 1st Interchange, Sheikh Zayed Road, P.O. Box 117781, Dubai, United Arab Emirates

3 Department of Financial Management, National Defense University, No. 70, Sec. 2, Zhongyang North Rd, Beitou, Taipei 112, Taiwan 